\title{
CÓMPUTO, RETRIBUCIÓN Y OTRAS CUESTIONES DE INTERÉS EN MATERIA DE PERMISOS
}

\author{
Carolina Blasco Jover \\ Prof $^{\text {a }}$ Titular Dpto. Derecho del Trabajo y de la Seguridad Social \\ Universidad de Alicante
}

\begin{abstract}
El disfrute de los permisos, pese a ser una cuestión de orden menor en comparación con otras de mayor calado, genera multitud de problemas prácticos que conviene resolver. Aquí, se prestará atención a dos de ellos por su especial incidencia: la determinación del período de duración de los permisos y qué concretos conceptos debe incluir el salario a percibir. Finalmente, se abordará un tema también controvertido: los necesarios ajustes que deben realizarse en el redactado legal para dar cabida a las parejas de hecho y para afrontar ciertas cuestiones de género aún pendientes de resolver.

Despite being a minor issue compared to others of greater depth, compensate absences create many practical problems that should be solved. Here, attention will be paid to two of them due to their special incidence: how to calculate the length of absences and what specific concepts the salary to be received should include for untaken leave. Finally, a controversial issue will be addressed: the necessary adjustments that must be made in the law to accommodate common-law couples and to address certain gender issues that are still pending of resolution.
\end{abstract}

Title: How to calculate, payment and other issues of interest about compensate absences?

Palabras clave: permisos, duración, salario, género, parejas de hecho

Keywords: compensate absences, length, salary, gender, common-law couples.

IUSLabor 3/2020, ISSN 1699-2938, p. 148-174.

DOI. 10.31009/IUSLabor.2020.i03.06

Fecha envío: 26.08.2020 | Fecha aceptación: 14.10.2020 


\section{Sumario}

1. A modo de introducción.

2. Inicio y cómputo de los permisos retribuidos: ¿punto final al debate? Tal vez no.

2.1.Primera línea interpretativa: el permiso debe comenzar a computarse en cuanto acontezca el hecho que lo motiva, sin distinguir si ese día inicial es laboral o no.

2.2.La ruptura con el principio de inmediatez: el primer día laborable desde el inicio del hecho causante como dies a quo.

2.3.La derivada más lógica: todos los días de permiso, el inicial y los posteriores, deben ser laborales.

2.4.El delicado equilibrio entre el derecho a ausentarse del trabajo y la necesaria relación de inmediatez entre el hecho causante y el disfrute del permiso: conformando otra opción interpretativa.

3. La retribución durante los permisos: ¿qué incluye el salario a percibir? El favor por la indemnidad retributiva.

4. Otras reformas pendientes: la equiparación de las parejas de hecho y la reformulación de ciertas expresiones con impacto de género. 


\section{A modo de introducción.}

Mucho se ha debatido tanto a nivel doctrinal como judicial del art. 37.3 ET y de los permisos que en él se contemplan, lo que ha contribuido a perfilar con mayor detalle sus contornos, a menudo un tanto difusos o abstractos. También han sido ímprobos los esfuerzos del legislador por ir adaptándolos, si bien no a todos, a las cambiantes realidades sociales, siendo el ejemplo más paradigmático de ello el permiso para el cuidado del lactante cuya evolución a lo largo del tiempo ha sido muy llamativa. Ahora bien, que ello sea así, que se hayan realizado tales esfuerzos, no quiere decir que aún no quede camino por recorrer y multitud de soluciones jurídicas que aplicar a problemas que se plantean en la vida cotidiana, social y laboral, de los trabajadores que se encuentran en la tesitura de ejercitar tales licencias.

A estos efectos, de entre la variada gama de cuestiones que pueden abordarse cuando de permisos se trata, este trabajo se centra en unos muy particulares. En primer lugar, se intentará ofrecer solución a tres problemas interpretativos que se plantean en cuanto al disfrute de estos derechos, a saber, cuál deba ser el día de inicio de su ejercicio, cómo deben computarse los días que se conceden y cuál haya de ser la retribución que deba percibir el trabajador durante ese tiempo del que dispone. Son cuestiones todas ellas que han saltado a la actualidad de la mano de los Tribunales y que, por su interés práctico para empresas y trabajadores, conviene tener muy claras. Porque, aunque parece existir ahora una línea jurisprudencial meridianamente consolidada al respecto, lo cierto es que, en mi opinión y adelantando ya una premisa que después se desarrollará, existen argumentos, creo que bastantes, para no dar por zanjado ninguno de estos asuntos. Argumentos que conducirían irremediablemente a acometer una reforma del art. 37.3 ET que aclare los diversos asuntos en materia de retribución y de duración de los permisos que el redactado del precepto deja en el aire; pero reforma que también se aproveche -y este es el segundo de los asuntos que se tratan en este trabajo- para entrar también de lleno en la eliminación de ciertas formulaciones que inciden en la perpetuación de los sesgos de género y en la necesaria equiparación en el redactado legal entre parejas de hecho y parejas unidas por vínculo conyugal. La toma en consideración tanto de ciertas realidades sociales actuales como del impacto de género que ciertos permisos pueden tener no son, en absoluto, cuestiones de menor importancia. De hecho, ese impacto de género al que se alude incluso tiene su reflejo en materia retributiva, pues, si nos atenemos a cierta línea judicial, la mayor o menor cuantía económica que se perciba puede depender -y mucho- de si el concreto permiso se ha configurado o no como neutro en términos de igualdad entre hombres y mujeres.

Las páginas que siguen se dedican, pues, al análisis de todas estas cuestiones, donde, por decirlo de otro modo, se ofrecerán argumentos para que los permisos en general y 
determinados de ellos, en particular, puedan ser objeto de una nueva configuración de modo tal que resulten de mayor utilidad práctica para los trabajadores al abarcar más supuestos, eliminarse ciertas disfuncionalidades y despejar ciertas dudas interpretativas en cuanto a su modo de disfrute.

\section{Inicio y cómputo de los permisos retribuidos: ¿punto final al debate? Tal vez no.}

Los términos del debate cuando se hace referencia a la problemática del inicio y cómputo de los permisos retribuidos parten, como es conocido, del redactado del art. 37.3 ET y, más en concreto, de las previsiones de las letras a), b) y c) de este precepto, que expresan la duración de la concreta licencia (matrimonio, infortunios familiares y mudanza) en días. Pues bien, a salvo del permiso por matrimonio en el que se especifica que los días deben ser naturales, en el resto nada se señala (¿son días hábiles o naturales?), por lo que el legislador deja abierta aquí la puerta a la interpretación y, por ende, a la controversia. No obstante, no es ésta la única cuestión a desentrañar, ya que el cómputo en días exige determinar cuál es el concreto dies a quo y dilucidar qué ocurre si existe solapamiento entre los días de permiso y los días de vacaciones o descanso del trabajador.

Como se ha dicho, son todas ellas cuestiones que, por la ambigüedad de la norma, han generado un encendido debate doctrinal y jurisprudencial, pero debate que parece haberse resuelto a la luz de las últimas resoluciones judiciales, ya del Tribunal Supremo, ya del Tribunal de Justicia de la Unión Europea o ya sean de la Audiencia Nacional. De esta forma, se parte de la base de que la concesión del permiso sólo tiene sentido si el acontecimiento que lo activa coincide en día de trabajo pues será sólo en ese momento cuando el empleado requiera ausentarse de su puesto, como indica el encabezado del art. 37.3 ET. Y si ello es así, la conclusiones no pueden mostrarse más evidentes: el día de inicio del permiso debe ser el día hábil siguiente a aquel en que sucede el hecho causante si éste acontece en día festivo o de descanso del trabajador, los días a computar deben ser solamente los hábiles porque sólo en ellos se prestan servicios y en modo alguno pueden compensarse los días de descanso o de vacaciones que hayan coincido con el acaecimiento del hecho causante porque el trabajador ha dispuesto de tiempo libre para atender la circunstancia que se le haya planteado.

Ahora bien, llegar al criterio interpretativo que se ha expuesto supone, evidentemente, la ruptura con otro criterio sobre el que en sede judicial se ponía el acento: la necesidad de que exista inmediatez entre el acontecimiento que activa el permiso y su disfrute. Por este motivo y por otros que después se señalarán entiendo que puede ser objeto de cierta crítica el nuevo planteamiento que a nivel judicial se sigue y que de buen seguro hará modificar numerosas cláusulas convencionales a partir de ahora. Por ello, y para enmarcar de mejor forma los argumentos que después se emplearán para rebatir la nueva línea 
jurisprudencial, parece conveniente realizar, si quiera brevemente, un apunte sobre los vaivenes judiciales que, hasta llegar a este momento, se han ido sucediendo.

\subsection{Primera línea interpretativa: el permiso debe comenzar a computarse en cuanto acontezca el hecho que lo motiva, sin distinguir si ese día inicial es laboral o no.}

Partiendo del hecho de que el Estatuto no ha perfilado la forma concreta en que deben disfrutarse los permisos, la lógica imperante en un primer momento fue considerar que aquéllos debían activarse, a salvo de previsión convencional en sentido contrario, justo cuando concurriera la necesidad del asunto en cuestión y siempre que ésta no pudiera ser atendida fuera de las horas de trabajo. ${ }^{1} \mathrm{Si}$ así fuera, esto es, si no existiera coincidencia horaria entre la prestación de servicios y la concreta necesidad, debía entenderse -puede decirse que por defecto- que el trabajador dispondría de tiempo suficiente, de tiempo libre, para atender al hecho causante. ${ }^{2}$ Así las cosas, desde esta perspectiva resulta del todo punto irrelevante que el día del evento que activa el permiso sea o no laborable para el trabajador. Lo verdaderamente importante es que concurra la necesidad y que la misma tenga que ser atendida en horas de trabajo. Y ello porque, para poder utilizar la licencia por la causa de que se trate, la norma fija como presupuesto la prestación efectiva de servicios. Sólo así podrá tener sentido la petición del trabajador de ausentarse del trabajo.

En correlación a esto y por lo que se refiere al cómputo de los días de licencia, comúnmente se admitía que éste se realizara por días naturales. De este modo, se entendía que, a pesar de que sólo el permiso por matrimonio venía referenciado en días naturales, la misma regla podía aplicarse al resto de licencias expresadas únicamente en "días". Dos eran básicamente los argumentos que, interconectados entre sí, se barajaban a favor de esta idea. El primero de ellos pivotaba sobre el hecho de que el concreto estado de necesidad que activa el permiso no entiende de días laborales o naturales. Una institución como la de los permisos surge, desde esta óptica, para satisfacer una determinada situación que acontece en un momento también muy concreto, puntual, y cuya atención no puede diferirse en el tiempo. Y si esto así ha de entenderse, la licencia ha de utilizarse entonces cuando resulte necesaria, por lo que si el período de disfrute llegara a abarcar festivos o sábados y domingos, no podría pretenderse que estos días se descontaran del plazo, pues cada día transcurrido sería día consumido. Dato éste que cobra especial relevancia si se tiene en cuenta que, con este planteamiento inicial, sólo si la concreta incidencia de que se trate se superpone con el horario laboral del trabajador, será cuando

\footnotetext{
${ }^{1}$ STS de 17 de enero de 2008 (Rec. n. ${ }^{\circ}$ 24/2007) y SSTSJ Navarra, de 21 de septiembre de 2006 (Rec. n. ${ }^{\circ}$ 253/2006), Cataluña, de 12 de marzo de 2003 (Rec. n. ${ }^{\circ}$ 1047/2002) y País Vasco, de 20 de septiembre de 1994 (Rec. n. $\left.{ }^{\circ} 1721 / 1994\right)$.

${ }^{2}$ Así, se entendió que una gestión matutina no provoca la necesidad de un permiso a un trabajador del turno de tarde (STCT de 18 de mayo de 1983, RTCT 5032/1983).
} 
éste habrá de tramitar su ausencia al trabajo. Ahora bien, ¿ve por ello el trabajador menoscabados sus derechos? En teoría, no, en tanto que ya sea ese día festivo, día de descanso semanal o de vacaciones el empresario ha de mantener la retribución, por lo que la única diferencia, sin entrar ahora en otras consideraciones, es que ese concreto empleado no tendrá que tramitar en esos días petición alguna de ausencia al trabajo. ${ }^{3}$

Por su parte, el segundo argumento se sustentaba en lo dispuesto en el número dos del artículo 5 del Código Civil (en adelante, CC), norma, como se conoce, de aplicación supletoria en caso de insuficiencia normativa. Pues bien, la letra del precepto mencionado conduce a pensar, igualmente, que, tratándose de computar un plazo en el seno de una relación claramente privada, como es la derivada del contrato de trabajo, debe realizarse el conteo de días por jornadas naturales, sin exclusión de festivos u otros análogos. La consecuencia de aplicar también este razonamiento ha sido la negación de todo derecho del trabajador a que el disfrute de su permiso se desplazara a los días laborales inmediatamente posteriores al hecho causante si la causa que detonaba la solicitud se desarrollaba durante uno o varios días no laborables. ${ }^{4}$

Con todo, cuestión distinta sería, como se dejó más arriba apuntado, la posibilidad reconocida a la negociación colectiva de mejorar este régimen jurídico legal, estableciendo que el cómputo del día inicial se realice a partir del primer día laboral y que se compute el resto de días como hábiles. Ahora bien, ello en el bien entendido de que la norma que instaurara este sistema expusiera de forma expresa y clara la posibilidad de

\footnotetext{
${ }^{3}$ Se ha dicho al respecto que en el supuesto de no poder disfrutar de los días de permiso en el momento de que se trate constituye "un caso fortuito del artículo 1105 del Código Civil por el que nadie debe responder perdiéndose por tanto tal derecho" (STSJ País Vasco, de 20 de septiembre de 1994, Rec. n. ${ }^{\circ}$ 1721/1994). ${ }^{4}$ SSTCT de 24 de marzo de 1982 (RTCT 1805/1982), de 3 de marzo de 1982 (RTCT 2065/1982) y de 12 de junio de 1980 (RTCT 3457/1980) y SSTSJ Galicia de 30 de mayo de 2008 (Rec. n. ${ }^{\circ}$ 1276/2008) y Cataluña, de 18 de junio de 2002 (Rec. n. ${ }^{\circ}$ 7823/2001). Con todo, cabe indicar la presencia entre la doctrina judicial de cierta línea argumentativa más flexible que consistiría en entender que cabe disfrutar del derecho incluso en momentos posteriores a la celebración de las nupcias o al acaecimiento de otro hecho causante, siempre y cuando su ejercicio se produjera acomodándose a los principios de la buena fe y no constituyera abuso de derecho de su titular frente al obligado por el derecho al permiso, el empresario. Es decir, siempre que el derecho continuase vivo (no extinguido por acción de la prescripción), no existiese intención alguna de causar perjuicio a la empresa o a su organización de trabajo y, en todo caso, siempre que se cumpliese con los requisitos formales de preaviso y justificación que se exigen legalmente. $\mathrm{Y}$ es que es posible pensar en supuestos en los que, celebrada la boda, no se pueda cumplir la finalidad del permiso, al verse obligados los esposos, por ejemplo, a vivir en casas distintas y no poder iniciar una vida en común. Por todas y en este sentido, pueden verse sobre el disfrute diferido del permiso por matrimonio las SSTSJ Cataluña, de 12 de marzo de 2003 (Rec. n. ${ }^{\circ}$ 1047/2002) y La Rioja, de 9 de febrero de 2010 (Rec. n. ${ }^{\circ}$ 31/2010) en la que se admite el disfrute del permiso por matrimonio dos meses y medio después de celebrarse las nupcias y, sobre el permiso por fallecimiento, la STSJ Madrid, de 13 de julio de 2004 (Rec. n. ${ }^{\circ}$ 2150/2004) que estima el recurso del trabajador para disfrutar, tras su vacaciones, de la licencia aun habiendo transcurrido dos meses después del óbito.
} 
disfrute tardío del permiso, acotando siempre un determinado período de tiempo dentro del cual podría llevarse a efecto. Permitir lo contrario supondría, para la praxis judicial de aquel momento ${ }^{5}$, tanto como vaciar al permiso de su contenido por desconectarlo de la finalidad para la que fue creado.

\subsection{La ruptura con el principio de inmediatez: el primer día laborable desde el inicio del hecho causante como dies a quo.}

El Tribunal Supremo, en sentencia de 13 de febrero de $2018^{6}$, va a cambiar o, al menos, modular su previa doctrina sobre el inicio del periodo de disfrute de los permisos expresados en días, considerando que comienzan a disfrutarse, no necesariamente en el día en que se produzcan los hechos y en los inmediatos siguientes, sino desde el primer día laborable siguiente al hecho causante cuando tal evento sucede en un día no laborable. Es esta una tesis que ya había encontrado su hueco en lo que concierne al permiso por matrimonio. Y es que, como se conoce, una de las cuestiones que, en su momento, fue objeto de mayor polémica fue la relativa a si el día de la boda debía o no computarse dentro de los quince días que se conceden. En una primera etapa, se contempló la posibilidad de que tal día se computara, con lo que, coincidieran o no las nupcias en jornada hábil o inhábil, ese día ya había que restarlo de los quince puestos a disposición del trabajador con ocasión de su enlace. Pues bien, este criterio interpretativo se modificó tras la aparición de la STS de 12 de mayo de 20097, que, adoptando un criterio salomónico, vino a diferenciar entre dos situaciones. Por un lado, si el día de la celebración coincidía con día laborable, había de entenderse que el día de las nupcias se contabilizaría a efectos de la duración del permiso, descontándose, en consecuencia, tal fecha de los quince días de licencia. Ocurriendo la situación contraria, esto es, que la fecha del enlace coincidiera con día libre del trabajador, se debía entender, en estos casos, que el período de disfrute del permiso habría de iniciarse desde el día hábil siguiente.

Parece poco dudoso, en consecuencia, que la extensión de la tesis que antecede a todas las licencias expresadas en días (o, más en concreto, a las correspondientes por infortunios familiares) obedece a la idea de otorgar un tratamiento unitario a la institución que disipe las principales dudas aplicativas al respecto. Para ello, se emplea el mismo argumento que sustenta la doctrina anterior (la norma fija como presupuesto para que pueda activarse

\footnotetext{
${ }^{5}$ STS de 17 de enero de 2008 (Rec. n..$^{\circ}$ 24/2007).

${ }^{6}$ Rec. n. ${ }^{\circ}$ 266/2016. Esta sentencia anula y casa la SAN de 13 de julio de 2016 (Proc. n. ${ }^{\circ}$ 183/2016), en la que aún se seguía la tesis anterior de la inmediatez del disfrute del permiso con el hecho causante. Sobre esta sentencia, puede verse el trabajo de Carlos González González, "La fecha inicial del disfrute de los permisos retribuidos. A propósito de la sentencia del Tribunal Supremo n ${ }^{\circ}$ 145/2018, de 13 de Febrero", Aranzadi Doctrinal, n. ${ }^{\circ}$ 7, 2018, pp. 129-141.

${ }^{7}$ Rec. n. ${ }^{\circ} 4 / 2008$.
} 
el permiso la prestación efectiva de servicios), pero llevándolo al extremo o, si acaso, dándole la vuelta: como el permiso sólo tiene sentido si se emplea cuando el trabajador está en su puesto de trabajo en tanto que, de lo contrario, no podría ausentarse de él como indica el art. 37.3 ET, el día inicial del permiso debe coincidir con día laborable. Por lo tanto, si el hecho causante se produce en "día feriado" (sinónimo de "día festivo") ${ }^{8}$, el disfrute del permiso debe diferirse "al primero que siga a ese día feriado". Entender lo contrario según este discurso, entender que cada día transcurrido es un día consumido, podría llevar al extremo de vaciar de contenido a la institución de darse la circunstancia de que el hecho causante se desencadenase al inicio de varios "días feriados" seguidos, pues el trabajador, en estos casos, perdería la licencia, no podría disfrutarla.

Como se observa, aunque se emplea prácticamente la misma premisa que con la anterior doctrina, el enfoque cambia, pues ya no se pone tanto el acento en que deba existir inmediatez entre el hecho causante y el disfrute del permiso, sino en la propia finalidad del permiso: si se concede para que el trabajador pueda interrumpir su prestación laboral, mal podrá hacerlo cuando no tiene obligación de trabajar. En consecuencia, carece de lógica, desde esta óptica, conceder la licencia o, más correctamente, iniciar el conteo de días cuando el hecho causante acontece en uno en el que no existe aquella obligación. Con todo, nótese que el planteamiento que antecede sólo es válido para sustentar la tesis de que el primer día de permiso debe ser día laborable, nada más. Ninguna referencia existe en la resolución antes citada a cómo deben computarse el resto de días, por mucho que quepa inferir de ella, leyendo entre líneas, que el resto de días de permiso deban ser laborales. Y tampoco se resuelven otras dudas que deja planteadas este nuevo enfoque. Dudas que provienen principalmente de la utilización del término "día feriado". Como se ha dicho, parece que día feriado ha de ser entendido como día festivo; no obstante, a mi juicio y para no restar coherencia al discurso que se sigue, creo que es factible tomar postura a favor de la tesis de vincular el disfrute de los días del permiso con aquellos que sean laborales para el trabajador afectado, determinando que, aunque sea día hábil para la empresa, si es día no laborable para el trabajador no debe computarse. ${ }^{9}$ Ahora bien, las incertidumbres no acaban aquí. Porque ¿habría que entender que, tras unas vacaciones o una baja por enfermedad durante las que hubiera acontecido el hecho causante del permiso, el trabajador podría solicitar el disfrute de la licencia una vez reincorporado al trabajo? Parece que la respuesta deba ser negativa porque lo contrario podría conducir a resultados poco acomodados a la finalidad de la institución y a la necesidad de que exista inmediatez entre el hecho causante y el disfrute de la licencia. Y dejando esto a un lado, también podría generarse cierta incertidumbre en términos de equidad o igualdad entre

\footnotetext{
${ }^{8}$ ATS de 10 de mayo de 2018 (Rec. n. ${ }^{\circ}$ 266/2016).

${ }^{9}$ Parece que en el mismo sentido, Carmen Sánchez Trigueros: “¿Puede posponerse el disfrute de los permisos por razones familiares al momento en que se debería trabajar?", Revista de Trabajo y Seguridad Social CEF, n. ${ }^{\circ} 424,2018$, p. 140.
} 
los trabajadores de una misma empresa porque según aconteciera el hecho causante en uno u otro día (día feriado o no) se dispondría de más o menos tiempo para atender la circunstancia que fuera ${ }^{10}$.

En cualquier caso, lo cierto es que tal criterio interpretativo del día de inicio de disfrute del permiso no ha sido uniforme en la praxis judicial. Así, de forma coetánea a la sentencia del Tribunal Supremo aparecieron tres resoluciones de la Audiencia Nacional ${ }^{11}$ que vendrían a matizar la tesis del primer día laborable como dies a quo. El enfoque parte, de nuevo, de considerar el tenor literal del art. 37.3 ET, pero poniendo el acento esta vez en la mención "días naturales" y "días". Se argumenta de este modo que si el legislador ha querido diferenciar entre un permiso, el de matrimonio, y los restantes es porque su voluntad fue la de otorgar a las licencias previstas en el precepto estatutario un distinto tratamiento jurídico. De esta forma, estaría, por un lado, el "permiso largo" por matrimonio en cuyo cómputo se deben incluir por expreso mandato legal (y a salvo de que el convenio estipule algo distinto) días laborales y no laborables empezando a contar desde el día de las nupcias como hecho causante que lo motiva. Por otro lado, estarían los "permisos cortos" o de "corta duración" que, como nada se señala expresamente sobre ellos, habrían de ser computados en días hábiles ya que, pudiendo el legislador haberlos equiparado a la licencia por matrimonio, no optó por ello. La consecuencia lógica de este planteamiento es aplastante por lo que se refiere al dies a quo de estas licencias: deben iniciarse en día laborable, por lo que si el hecho causante acontece en día que no lo es, el disfrute del permiso debe diferirse al primer día laborable desde aquél. Y ello no obstaría, al decir de la Sala, a la finalidad de estas licencias, por cuanto el hecho que las desencadena supone para el trabajador la realización de ciertas gestiones que normalmente no podrá llevarlas a cabo en tiempo inhábil y para las cuales necesitará ausentarse de su trabajo de forma necesaria.

Como se observa, son dos los criterios interpretativos que emplean estas resoluciones para basar su fundamentación. Primero, el recurso a la interpretación literal del art. 37.3 ET a la que se le vincula una pretendida intención del legislador. Segundo, el elemento causal que aparece en los "permisos cortos", una finalidad, la de atender ciertas contingencias acaecidas en tiempo de trabajo, de la que extraer que sólo en ellos el trabajador necesita ausentarse de su puesto. Esta misma finalidad o razón de ser no

\footnotetext{
${ }^{10}$ Piénsese en el supuesto en que el fallecimiento de un familiar ocurra en viernes, día no laborable para el trabajador según su cuadrante de trabajo. Debería reincorporarse el martes. Pues bien, este trabajador habría dispuesto del fin de semana y del lunes para atender las necesidades del sepelio, pero resulta que el permiso le empezaría a computar desde el martes, por lo que no se reincorporaría hasta el jueves. No obstante, si el fallecimiento aconteciera un martes, ese mismo trabajador dispondría tan sólo de dos días, debiendo reincorporarse el jueves.

${ }^{11}$ SSAN de 13 de junio de 2018 (Proc. n. ${ }^{\circ}$ 91/2018), de 20 de junio de 2018 (Proc. n. ${ }^{\circ}$ 94/2018) y de 28 de junio de 2018 (Proc. n. ${ }^{\circ}$ 105/2018).
} 
aparecería en la licencia por matrimonio, similar, al decir de la Sala, a unas vacaciones y cuya finalidad estaría más que cumplida con la concesión de "dos semanas sin trabajo". Sin duda, es la que se plantea otra forma de situar y resolver el problema del inicio y cómputo de los días de permiso, pero que, a mi modo de ver, adolece de dos defectos: obvia, de un lado, de forma flagrante lo dispuesto en el art. 5.2 CC-como creo, por cierto, que también lo hace la tesis mantenida por el Tribunal Supremo- y anuda, por otra parte, ciertas finalidades a los distintos permisos simplemente por el hecho del olvido de incorporar un adjetivo a la mención "días" de las letras b) y c) del art. 37.3 ET que quizá, y sólo quizá, no se ajuste a lo realmente pretendido por el legislador.

\subsection{La derivada más lógica: todos los días de permiso, el inicial y los posteriores, deben ser laborales.}

Sea como fuere, lo cierto es que el criterio mantenido por el Tribunal Supremo en 2018 sobre el dies a quo ha sido reiterado en dos de sus sentencias más recientes. ${ }^{12}$ Se parte de la premisa, de nuevo, de que los permisos tienen como presupuesto básico que el trabajador deba ausentarse de su puesto de trabajo. Ese es el eje sobre el que se construye toda la argumentación. Por lo tanto, si el hecho causante acontece en un día no laborable, entendido por la Sala como aquel día que es "festivo o establecido como no laborable en el calendario laboral", el cómputo del permiso debe iniciarse en el día laborable inmediato pues es cuando tendrá sentido solicitar un permiso para dejar de prestar servicios. Y, a la inversa, si el acontecimiento que activa la licencia se desencadena en día laborable, el permiso podrá disfrutarse desde ese mismo día. ¿Y qué ocurre con el resto de días del permiso? Pues lo único que, siguiendo este planteamiento, cabía inferir: todos los días del permiso deben entenderse como laborales, salvo, eso sí, previsión normativa en contrario, que es justo lo que sucede con la licencia por matrimonio. En consecuencia, para el resto de permisos, deben excluirse del cómputo todos aquellos días en los que no se trabaje, en los que no exista obligación de prestar servicios y, por ende, de solicitar una licencia, es decir, los días de descanso semanal, las vacaciones, los festivos o los días en los que el contrato, por cualquier causa, esté suspendido.

Así las cosas, puede decirse que la ruptura con la tesis tradicional anterior se consolida, yéndose, incluso, un paso más allá. Ahora bien, la duda se abre de inmediato porque ¿dónde queda entonces la tan preconizada relación de causalidad que debe mediar entre el permiso y el hecho que lo activa? De hecho, muy fácilmente pueden pensarse en situaciones en las que, debido al disfrute diferido del permiso, éste ya no sea necesario porque se han cumplido con las exigencias propias de cada evento que origina la licencia. Pues bien, la cuestión no es que quede definitivamente zanjada, pero sí que es cierto que

${ }^{12}$ SSTS de 11 de marzo de 2020 (Rec. n. ${ }^{\circ}$ 192/2018) y de 17 de marzo de 2020 (Rec. n. ${ }^{\circ}$ 193/2018). Estas sentencias casan y anulan las SSAN de 20 de junio y de 13 de junio de 2018, respectivamente. 
parece apuntarse en una dirección: los permisos se deberán utilizar en días laborables... pero siempre y cuando subsista la necesidad que cubre el permiso. ${ }^{13}$ Siendo esto así, es claro que para cada permiso deberá estarse a las circunstancias que rodean la justificación de su concesión, algo que, a mi juicio, podría introducir cierta confusión en la aplicación de las previsiones del art. 37.3 ET. En efecto, en algunos permisos puede verse muy claro que la necesidad ya ha decaído (una mudanza realizada un domingo no generará derecho al permiso el lunes hábil siguiente), pero no en otros en los que será necesario un esfuerzo de verificación por parte del trabajador o, en caso de duda, del órgano judicial. ${ }^{14} \mathrm{Y}$, es más, visto el asunto desde otra perspectiva, parece que ni tan siquiera con el mantenimiento de la tesis de la subsistencia de la necesidad quedaría totalmente neutralizada una de las críticas que anteriormente se realizaban, que unos trabajadores puedan disponer de más "días libres" - por así decirlo-que otros para los que la casualidad haya hecho que el evento causante coincida únicamente en día o días laborables.

Por lo demás, obsérvese que se explicita, ahora ya sí, qué deba entenderse por día no laborable: aquél que concurra en "festivo o día establecido como no laborable en el calendario laboral". Sucede, sin embargo, que llevar hasta el último extremo este planteamiento supondría desvirtuar en cierta forma la tesis por la que se aboga, que es la necesidad de que el trabajador deba ausentarse del trabajo para que el permiso responda a su causa y finalidad. Por lo tanto, resulta más factible pensar que por "día no laborable" deba entenderse todo aquel día en que el trabajador no tiene la obligación de prestar servicios, tal y como se apuntó más arriba y como también indica, por cierto, la última sentencia dictada hasta la fecha en materia de cómputo de los días de permiso, la SAN de 6 de julio de 2020. ${ }^{15}$ Así pues, se trataría de atender, no tanto al calendario laboral de la empresa, sino al concreto cuadrante de trabajo del empleado. Sólo apostando por esta forma de considerar cuáles sean los días laborales o no laborales podrá tener sentido la doctrina del disfrute de los permisos (salvo el de matrimonio) en días hábiles.

\footnotetext{
${ }^{13}$ Señala la STS de 11 de marzo de 2020 (Rec. n. ${ }^{0}$ 192/2018) que "como premisa general hay que aceptar que el permiso sólo tiene sentido si sirve para atender a la causa que lo permite, de ahí que se exija cierta inmediatez entre la necesidad que cubre el permiso y el efectivo disfrute de éste".

${ }^{14}$ Piénsese, por poner un ejemplo, en un fallecimiento que acontece en sábado. El trabajador dispondría del fin de semana para realizar las gestiones oportunas derivadas de ese acontecimiento, por lo que el lunes ya tendría que reincorporarse a su puesto de trabajo. No obstante, podría plantearse como hipótesis que el entierro no se haya podido efectuar habida cuenta de que los domingos, en la localidad de que se trate, no se ofician sepelios o el cementerio no está abierto. Ese trabajador deberá solicitar el disfrute del permiso el lunes por ser un día en el que aún subsiste la necesidad que ampara el derecho.

${ }^{15}$ Proc. n. ${ }^{\circ} 113 / 2018$. Expresamente esta sentencia se refiere a "días hábiles para el trabajador". Sobre esta sentencia, vid. Eduardo Rojo Torrecilla: "Previsible final de la saga "¿disfrute de permisos en días laborables o naturales?". Notas a la sentencia de la AN de 6 de julio de 2020, tras la sentencia del TJUE de 4 de junio (asunto C-588/18), y recordatorio de la conflictividad jurídica anterior”, El blog de Eduardo Rojo (en línea), 30 de julio de 2020 (http://www.eduardorojotorrecilla.es/2020/07/previsible-final-de-la-sagadisfrute-de.html; 3 de agosto de 2020).
} 
Necesidad de ausentarse del trabajo y exigencia de cierta inmediatez entre el hecho causante y el disfrute del permiso son, pues, los dos criterios que, en un delicado equilibrio, parece que deben conjugarse para no obstar a la finalidad a la que sirven las licencias retribuidas. Y criterios que, desde esta perspectiva aplicados, son los que también sirven para zanjar otra cuestión polémica en la materia ya avanzada en páginas precedentes: la superposición entre el hecho causante del permiso y las vacaciones o cualquier otro supuesto interruptivo o suspensivo de la relación laboral. ¿Existiría un pretendido derecho del trabajador a disfrutar del permiso desde el primer día hábil siguiente al trascurso de tales situaciones? Evidentemente, tras lo expuesto, la respuesta negativa se torna, ahora ya sí, clara porque, tras los días de asueto, ninguna necesidad subsistiría. Ahora bien, la problemática, a la que oportunamente da respuesta la sentencia antes citada, no es en absoluto baladí, en tanto que ofrecer una solución como ésta puede chocar frontalmente con la finalidad que de suyo tienen las vacaciones o, en su caso, el descanso semanal. A estos efectos, no se desconoce la rotundidad con la que al respecto se ha pronunciado el Tribunal de Justicia ${ }^{16}$, sentenciando que los arts. 5 y 7 de la Directiva 2003/88/CE no quedan vulnerados por el hecho de que exista un solapamiento entre los derechos en liza, vacaciones y descanso semanal por un lado y, por otro, permisos retribuidos. Lo que es tanto como afirmar, evidentemente, que si existiera tal coincidencia, los días de permiso quedarían absorbidos por tales períodos de inactividad laboral.

La respuesta ofrecida por el Tribunal de Justicia es certera, a mi parecer y ello tanto porque el permiso está ligado al tiempo de trabajo como por el hecho de que diferir su disfrute a un momento en el que ya no es necesario resulta del todo punto incoherente con la finalidad que con esta institución se persigue. E igualmente certera me parece también la posición por la que se opta de no extrapolar a esta problemática la tesis del disfrute extemporáneo de las vacaciones cuando éstas coinciden en el tiempo con una incapacidad laboral. Primero, porque la finalidad del derecho a disfrutar de un permiso es completamente distinta a la finalidad que tiene un proceso de incapacidad temporal, que es la necesidad de descansar para cuidar de la salud. Segundo, porque la premisa tanto en vacaciones como en la situación de incapacidad es que el trabajador no está prestando servicios, mientras que para solicitar un permiso se necesita que la relación laboral esté plenamente activa, ni interrumpida ni suspendida. Y tercero, porque nada obliga a que en

\footnotetext{
${ }^{16}$ STJUE de 4 de junio de 2020 (asunto C-588/18) en respuesta a la cuestión prejudicial planteada por el auto de la Audiencia Nacional de 3 de septiembre de 2018 (Proc. 113/2018) y siguiendo las conclusiones del abogado general dictadas al respecto. Acerca de la cuestión prejudicial, vid. el trabajo de Ana Belén Muñoz Ruiz: "El cómputo de los permisos retribuidos: una revisión de la doctrina judicial y de la reciente cuestión prejudicial", Trabajo y Derecho, n. ${ }^{\circ}$ 53, 2019, pp. 45-56.
} 
vacaciones o en descanso semanal el trabajador deba dedicar todo su tiempo al ocio y al esparcimiento. ${ }^{17}$

\subsection{El delicado equilibrio entre el derecho a ausentarse del trabajo y la necesaria relación de inmediatez entre el hecho causante y el disfrute del permiso: conformando otra opción interpretativa.}

Como se ha tenido oportunidad de comprobar, de esta forma planteado el asunto es una cuestión de prioridades, de poner en la balanza la ausencia al trabajo que de suyo conlleva el permiso y la necesaria inmediatez que debe existir entre éste y el hecho que lo desencadena. Las últimas resoluciones judiciales transitan por un modelo que intenta equilibrar ambas circunstancias, pero otorgando, a mi modo de ver, mayor relevancia a la premisa de que el permiso sólo tiene sentido cuando existe obligación de trabajar. Las primeras, por el contrario, hacían mayor hincapié en la relación de inmediatez, sin negar, no obstante, que debía existir coincidencia horaria entre la prestación de servicios y el suceso detonante.

El problema es que llevar hasta sus últimas consecuencias el nuevo planteamiento por el que se aboga en sede judicial implica admitir la inaplicación del art. $5 \mathrm{CC}$ en este punto. $\mathrm{Y}$, es que, en realidad y en mi opinión, gran parte de las dificultades presentes en la regulación del régimen jurídico de los permisos retribuidos y determinación de la forma de cómputo obtienen respuesta en dicho precepto (y, desde luego, podrían tenerla en la negociación colectiva). La norma que recoge tal precepto es supletoria, como se conoce, en el ámbito laboral y bien podría recurrirse a ella no sólo para determinar si los días de permiso son hábiles o inhábiles, sino también para fijar el dies a quo. Veamos.

Señala el art. 5.1 CC que "siempre que no se establezca otra cosa, en los plazos señalados por días, a contar de uno determinado, quedará éste excluido del cómputo, el cual deberá empezar en el día siguiente". Por su parte, el número dos de este mismo precepto indica que "en el cómputo civil de los plazos no se excluyen los días inhábiles". Pues bien, a mi entender, si estas previsiones son las que deben marcar las reglas del juego cuando existe una situación de carencia de regulación en las normas que disciplinan una relación privada, como es la laboral, han de resultar también de aplicación cuando del art. 37.3 ET estamos hablando. Y así, por lo pronto, partiendo de la necesaria relación de inmediatez

\footnotetext{
${ }^{17}$ Sobre la posibilidad de paralizar el disfrute de las vacaciones cuando acontece el acontecimiento que activa el permiso y reanudarlas posteriormente, vid. Carmen Sánchez Trigueros: "Sobre la superposición de permisos a descansos o vacaciones. Comentario a la Sentencia del Tribunal de Justicia de la Unión Europea de 4 de junio de 2020, asunto C-588/18”, Revista de Trabajo y Seguridad Social CEF, n. ${ }^{\circ} 451$, 2020 , p. 215.
} 
que debe existir entre el hecho causante y el disfrute de la licencia de que se trate, la respuesta a la pregunta de cuál debe ser el día inicial del permiso cabría encontrarla en el primer apartado de la norma civil. En tanto que nada se establece normativamente, cabría situar el dies a quo en el día siguiente del evento desencadenante. No, por lo tanto, en ese mismo día, pues ello supondría colocar en peor situación de partida, de forma injustificada, a los trabajadores a quienes se les produce el estado de necesidad durante el trabajo (o tras él) con respecto a los demás. Y ese día siguiente -por hilar el razonamiento- podrá ser hábil o inhábil para el trabajador, algo totalmente indiferente, puesto que, primero, por aplicación del segundo párrafo de la norma civil, los días deben computarse como naturales y, segundo, porque los hechos que motivan la ausencia del trabajador de su puesto pueden acontecer, como ya se tuvo ocasión de indicar, en cualquier momento, no entienden de días laborales o no laborales.

Precisamente, esta misma regla del cómputo por días naturales cabría aplicar cuando del disfrute de los permisos de la letra b) y c) del art. 37.3 ET se trata. Cierto es que la mención se hace a "días", sin más, y que si ello se contrapone a los "días naturales" del permiso por matrimonio parece darse a entender que el legislador ha pretendido un régimen distinto para una y otras licencias. No obstante, no puede obviarse que cuando opera el silencio normativo, ha de estarse a la supletoriedad del Código Civil que manda computar los días sin excluir los inhábiles. ${ }^{18}$ Pero es que, además, otros dos argumentos avalarían esta interpretación. Así, sólo cabe pensar que cuando el legislador ha pretendido que ciertos permisos se disfruten por días hábiles lo ha hecho constar expresamente. Fíjese, en este sentido, en lo que ocurre con el permiso por desplazamiento del art. $40.6 \mathrm{ET}$, en donde expresamente se señala que el trabajador dispone de "cuatro días laborables en su domicilio de origen por cada tres meses de desplazamiento". No obstante y si este argumento no fuera lo suficientemente sólido por estar referido a un artículo distinto del Estatuto, podría tenerse en cuenta también que el cómputo por días hábiles no sólo supondría desconocer el mandato civil, sino también una ampliación indirecta de las licencias cuyo coste habría de asumir irremediable y quizá injustificadamente el empresario y que ni tan siquiera se solventaría, como se apuntó, por el hecho de exigir que aún perviva la necesidad que motivó el permiso. Además, parece poco dudoso, tal y como también se adelantó, que planteado de esta forma el asunto podría generarse una mayor confusión entre empresas y trabajadores a la hora de determinar cuándo sigue subsistiendo la necesidad que motivó el permiso: ¿quién lo decide? ¿en base a qué parámetros? Piénsese, por poner un ejemplo, en el caso del fallecimiento: ¿cuándo debe entenderse que subsiste la necesidad? ¿Cuando aún no se han realizado todas las gestiones

\footnotetext{
${ }^{18}$ LAHERA FORTEZA, Jesús, "Ejercicio y cómputo de los permisos retribuidos. Comentario a las sentencias del Tribunal Supremo 229/2020 y 257/2020, de 11 y 17 de marzo", Revista de Trabajo y Seguridad Social $C E F$, n. $^{\circ} 448,2020$, p. 174.
} 
que conlleva un sepelio o cuando, acometidas éstas, aún, por decirlo así, no se ha llorado la perdida?

Corolario de lo expuesto, en fin, es que, iniciado el permiso, éste no habría ni de interrumpirse por el hecho de que los días siguientes coincidieran con días que no fueran laborales para la persona trabajadora ni de desplazarse para un disfrute posterior, puesto que, visto que la norma nada señala y de nuevo por aplicación de la regla civil, el disfrute de los permisos ni puede fraccionarse ni ser objeto de interrupción. Los convenios colectivos, obviamente, en su papel de mejora de las normas estatutarias, bien podrían modificar esta situación, pero, en cualquier caso y como se ha explicado, en mi opinión no es posible extraer de la aplicación de las normas consideradas más conclusiones que las que aquí se han plasmado si no se quiere violentar el sentido último de la institución. Lo deseable, ello no obstante, sería que se introdujera legislativamente algún tipo de previsión al respecto en el texto del art. 37.3 ET que clarificara, ya sea en un sentido o en otro, la intención del legislador estatutario de una vez por todas y sin margen de duda alguna. No se desconoce que cuando se ha tenido oportunidad de acometer tal reforma, no se ha hecho, pero lo cierto es que quizá no debería demorarse en demasía por los problemas aplicativos que entiendo genera el nuevo discurso judicial que se sigue.

\section{La retribución durante los permisos: ¿qué incluye el salario a percibir? El favor por la indemnidad retributiva.}

Como al comienzo se anunció, otra de las cuestiones más controvertidas del ejercicio de los permisos es la de la retribución. Todas las licencias del art. 37.3 ET (incluida la de exámenes, si así se ha previsto convencionalmente) suponen el mantenimiento de la retribución. Ocurre, no obstante, que el precepto no proporciona los criterios que hayan de seguirse para determinar la cuantía en que debe retribuirse el tiempo empleado en el disfrute de estas licencias, lo que ha provocado cierta controversia judicial al respecto. Al respecto, existe cierta corriente ${ }^{19}$ que admite sin ambages que el trabajador que haga uso de estos permisos tendrá derecho a percibir su salario real, es decir, la misma cuantía remuneratoria, suma del salario base y de los diversos complementos salariales, que si hubiese prestado servicios de manera efectiva durante la jornada que tuviese prefijada para el día de licencia. Se ha entendido que ello sería así en la medida en que, admitir lo contrario, esto es, partir de la premisa de que el empresario únicamente tendría que abonarle al trabajador parte de su retribución diaria, justamente la que le correspondiera en proporción al tiempo realmente trabajado, podría provocar un efecto disuasorio en el

\footnotetext{
19 STS de 20 de mayo de 1992 (Rec. n. ${ }^{\circ}$ 1634/1991) y SSTSJ Navarra, de 29 de junio de 2006 (Rec. n. ${ }^{\circ}$

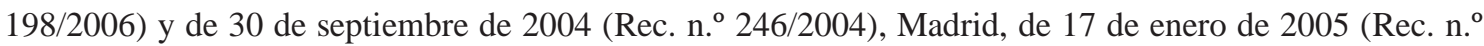
6305/2004) y Cataluña, de 16 de octubre de 2003 (Rec. n. ${ }^{\circ}$ 4232/2003), entre otras.
} 
ejercicio de estas licencias, en absoluto deseable por distorsionador de la finalidad para la que aquéllas fueron concebidas.

Visto de esta forma, entonces, esta ficción jurídica que se crea respecto de las horas no trabajadas habría de ser respetada por los convenios colectivos, a los que les estaría vedada la posibilidad de retribuir el tiempo de ausencia en una cuantía inferior al salario real del trabajador. En cualquier caso, existe, junto con esta línea judicial que aboga por el mantenimiento de la retribución total, otro grupo de resoluciones judiciales ${ }^{20}$ que vienen permitiendo que del montante que deban percibir los trabajadores ausentes por ejercicio de estos permisos se excluyan ciertos complementos salariales, precisamente los que, de algún modo, están conectados con la prestación efectiva de servicios o con la consecución de un cierto nivel de rendimiento, como, por ejemplo, pluses de festivos, de nocturnidad, de peligrosidad o primas de producción. Se argumenta que ello no supondría menoscabo alguno o penalización para el trabajador o vulneración de la finalidad pretendida con estos permisos, en tanto que los citados complementos únicamente encuentran razón de ser en un mayor esfuerzo realizado o en unas condiciones de trabajo menos ventajosas o incómodas, careciendo de sentido que se perciban cuando, en absoluto, se dan las circunstancias necesarias para su devengo.

De lo que antecede, pues, parece que pueda extraerse la conclusión de que no existiría en la práctica para el trabajador que se ausentase de su puesto de trabajo en estas circunstancias la garantía de que su retribución se mantuviera indemne. De hecho, nada obstaría, habida cuenta de los criterios interpretativos explicados, a que aquélla pudiera verse ocasionalmente reducida si se percibieran partidas económicas cuyo devengo trajera causa del desarrollo de la actividad o de la consecución de ciertos resultados. No obstante, cierto es que mantener un planteamiento como el que antecede supondría limitar la efectividad de los permisos al provocar en el trabajador tener que plantearse la disyuntiva entre tutelar determinadas necesidades primarias que tiene en cuanto persona o miembro de una unidad familiar o mantenerse en su puesto de trabajo sólo porque exista la posibilidad de percibir una retribución inferior a la habitual. Tal vez por ello se ha intentado pergeñar otra solución, pero esta vez desde una perspectiva sumamente particular, la de la igualdad de género y no discriminación. ${ }^{21}$ Veamos.

Se parte de la base de entender que existe un motivo por el que se deja en el aire el asunto de la retribución, que no es otro que el convenio disponga de la libertad suficiente como para incidir en cuál haya de ser el alcance y contenido de la remuneración que

\footnotetext{
${ }^{20}$ SSTS de 6 de marzo de 2012 (Rec. n. ${ }^{\text {o } 80 / 2011) ~ y ~ d e ~} 9$ de marzo de 2007 (Rec. n. ${ }^{\circ}$ 1968/2005) y SSTSJ Madrid, de 19 de julio de 2006 (Rec. n. ${ }^{o}$ 2793/2006), Cataluña, de 23 de enero de 2004 (Rec. n. ${ }^{\circ}$ 480/2002) y Cantabria, de 15 de febrero de 2000 (Rec. n. ${ }^{\circ}$ 94/2000), entre otras.

${ }^{21}$ STS de 3 de diciembre de 2019 (Rec. n. ${ }^{\circ}$ 141/2018).
} 
correspondería percibir durante los días de permiso. Desde ahí es razonable deducir que si la negociación colectiva opta por crear determinados complementos, ésta $-y$ no otradebe ser la vía idónea para establecer las condiciones en las que se genera el derecho a su percepción cuando el trabajador interrumpe su contrato a causa del disfrute de la licencia de que se trate. Pero ello con un claro límite, garantizar la efectiva igualdad de género. Frontera infranqueable ésta cuya rigurosa aplicación impone analizar permiso por permiso para comprobar el impacto de cada uno de ellos sobre tal principio y para determinar, a la postre, si éste sufre por la exclusión del complemento de que se trate durante los días de licencia.

Como se observa, este planteamiento renuncia a ofrecer una respuesta unívoca a la controversia sobre el montante que debe percibir el trabajador durante los días de permiso en pos de ofrecer un tratamiento jurídico diferenciado o individualizado para cada licencia de las contempladas en el art. 37.3 ET. Pero, ello no obstante, no hace falta agotar argumentos para constatar lo artificioso de esta separación entre derechos cuya base jurídica pretende ubicarse en el art. 4 Ley Orgánica 3/2007, de 22 de marzo, para la igualdad efectiva de mujeres y hombres. ${ }^{22}$ Pero, sin entrar ahora en ello, la duda se abre de inmediato porque ¿qué concretas licencias comportarían, en base a este planteamiento, ejercicio de derechos fundamentales, en especial, asociados a la no discriminación por razón de género? Prima facie, podría pensarse en el permiso por infortunios familiares (con la salvedad hecha del fallecimiento) habida cuenta tanto del rol de cuidadora que, aún hoy, se asocia a las mujeres como por la extensión del abanico de sujetos causantes a los familiares por afinidad que, como más tarde se comentará, puede contribuir a fomentar la desigualdad de género aún en mayor medida. ${ }^{23}$ En similar situación se encontraría el permiso para ausentarse del trabajo por el tiempo indispensable para la realización de exámenes prenatales y técnicas de preparación al parto o para asistir a las preceptivas sesiones de información y preparación o realización de los informes psicológicos y sociales previos a la declaración de idoneidad en los casos de adopción, guarda con fines de adopción o acogimiento. Y es que, aunque dirigida esta licencia a ambos miembros de la pareja, la eventual exclusión de algún complemento salarial en su disfrute podría provocar un efecto sin duda distorsionador por lo que atañe a la consecución del objetivo de la corresponsabilidad familiar tan necesaria para garantizar

\footnotetext{
${ }^{22}$ Se señala en este precepto que "La igualdad de trato y de oportunidades entre mujeres y hombres es un principio informador del ordenamiento jurídico y, como tal, se integrará y observará en la interpretación y aplicación de las normas jurídicas".

${ }^{23}$ De hecho, la STC 71/2020, de 29 de junio abunda en esta cuestión, pues dictamina que la denegación al trabajador del permiso por hospitalización con ocasión del parto de una pariente constituye una discriminación por asociación prohibida por el artículo 14 CE. Razona el Tribunal que la exclusión del ámbito material del artículo 37.3.b) ET de la hospitalización por parto supondría una discriminación directa por razón de sexo hacia la mujer hospitalizada; discriminación que, a su vez, proyectaría sus efectos perjudiciales hacia el pariente que solicita el permiso y lo ve denegado.
} 
la igualdad entre sexos. Por el mismo motivo, podrían añadirse a este bloque los permisos para el cuidado lactante y por hospitalización del hijo, aunque se encuentren como se conoce en apartados distintos del art. 37 ET.

¿Tienen, por su parte, el resto de permisos impacto en derechos o libertades constitucionales asociados con la igualdad de género y la no discriminación? Siguiendo con el planteamiento antes expuesto, parece que la respuesta debe ser negativa en el caso de las licencias por fallecimiento de familiar, cumplimiento de deber inexcusable de carácter público y personal o por ejercicio de funciones sindicales ya que ambos se conceden por hechos tan absolutamente ajenos a la igualdad, conciliación, corresponsabilidad o prohibición de discriminación que ningún impacto de género se aprecia en ellos. Más controvertido es el caso de las licencias por matrimonio y por traslado de domicilio habitual. Porque, por un lado, podría argumentarse que ambas licencias son objetivamente neutras en términos de circunstancias de género ya que afectan por igual a hombres y mujeres. Pero, esto es una forma de verlo... un tanto simplista, en mi opinión, porque si dos de las vías que conducen a la igualdad entre sexos (y a la eliminación de toda discriminación directa entre sexos) son, por un lado, la conciliación de la vida familiar y laboral y, por otro, la corresponsabilidad, bien podría pensarse que ambas licencias contribuyen, a su modo, a alcanzar ambos objetivos.

En cualquier caso y sin negar el esfuerzo interpretativo que esta tesis conlleva, lo cierto es que, como se adelantó antes, parece un tanto artificiosa la diferenciación efectuada entre un bloque de permisos y otro cuando de la letra del precepto no se deriva clasificación alguna. ${ }^{24}$ A estos efectos, a efectos de retribución, todas las licencias contempladas en el art. 37.3 ET, reciben un mismo tratamiento jurídico puesto que para todas alcanza ese genérico "derecho a retribución" que aparece en el encabezado del precepto estatutario. Y bien es verdad que la indeterminación normativa podría utilizarse para apostar por la flexibilidad retributiva, dejando a la negociación colectiva la tarea de concretar el salario a percibir durante los días de permiso. Pero, ello no obstante y tal y como se tuvo ocasión de exponer ante la problemática del inicio y cómputo de las licencias, este asunto es, también, una cuestión de límites. Límites que, de cruzarse, bien podrían conducir al extremo de -utilizando una frase anterior- violentar el sentido último de la institución. Porque primar (o premiar si se prefiere) unos permisos frente a otros, introducir dos categorías según conlleven o no la pérdida de algún complemento y restringir, a la postre, la utilización de derechos reconocidos legalmente introduce, en efecto, un elemento distorsionador en absoluto desdeñable en el ejercicio de ciertas licencias al colocar al trabajador en la difícil tesitura de sopesar las circunstancias y

\footnotetext{
${ }^{24}$ Se está de acuerdo, pues, con el voto particular que incorpora la STS de 3 de diciembre de 2019 (Rec. n. $\left.{ }^{\circ} 141 / 2018\right)$.
} 
decidir entre perder parte de su salario por atender según qué concretas necesidades u obviarlas y mantenerse en su prestación de servicios.

Por lo tanto, como quiera que de la letra de la norma no puede extraerse razón alguna para restringir o penalizar el disfrute de unas licencias en favor de otras, parece que lo más conveniente sea concluir que durante el período de disfrute de los permisos - de todos ellos- el trabajador tiene derecho a la totalidad de su retribución como si hubiera efectivamente prestado servicios durante ese tiempo. Y ya, si se quiere, pero traído a mayor abundamiento, podría argumentarse también que, cuando el disfrute del permiso responda a razones vinculadas con la vida personal y familiar del trabajador, una hipotética merma retributiva a quien ejercita su derecho a la ausencia podría suponer una vulneración del principio de igualdad de trato entre mujeres y hombres en tanto que, efectivamente, unas licencias, por su propia configuración y por la no superación todavía de determinados roles, son empleadas más por unas que por otros. Introducir de este modo la tesis de la discriminación indirecta no parece que resulte en absoluto forzado; pero lo que creo que no puede pretenderse es erigir este argumento en piedra de toque angular sobre la que construir dos categorías de derechos que la propia ley no ampara y permitir que una de ellas sufra en mayor medida que la otra sólo porque se la tacha de "neutra" a efectos del principio de igualdad de género y no discriminación.

\section{Otras reformas pendientes: la equiparación de las parejas de hecho y la reformulación de ciertas expresiones con impacto de género.}

Es evidente, tras lo explicado en las páginas precedentes, que tercia acometer una reforma del art. 37.3 ET que aclare los diversos asuntos en materia de retribución y de duración de los permisos que el redactado del precepto deja en el aire. Pero la modificación normativa por la que se aboga debe ir más allá para entrar también de lleno en otras cuestiones, en concreto, en la equiparación entre parejas de hecho y parejas unidas por vínculo conyugal y en la apuesta por eliminar ciertas formulaciones que inciden en la perpetuación de los sesgos de género.

Véase, al respecto, lo que sucede con el permiso por matrimonio. Es ésta, como se conoce perfectamente, una licencia que se concede a los trabajadores que han optado por un determinado modo de unión estable, la matrimonial, con la finalidad, precisamente, de facilitar la transición de un estado civil a otro. La circunstancia que activa este permiso, por lo tanto, está ligada al hecho de contraer nupcias. Ahora bien, el problema es evidente que se plantea cuando el trabajador opta por una fórmula de unión con su pareja distinta al acto del matrimonio. Y es que, no obstante las diversas oportunidades que ha tenido el legislador para modificar el tenor literal del precepto, lo cierto es que no lo ha hecho y las parejas de hecho no se encuentran incluidas en el radio de acción del art. 37.3.a) ET. Con 
todo y naturalmente, de lo anteriormente expuesto no cabe derivar que, a través de la negociación colectiva, no sea posible establecer otro régimen jurídico más favorable para el trabajador, habida cuenta de la naturaleza de norma mínima de este precepto. De hecho, existen actualmente multitud de convenios que admiten la concesión de esta licencia también a las parejas unidas a través de una fórmula distinta a la matrimonial, siempre y cuando cumplan con unos determinados requisitos, por ejemplo, la inscripción en el Registro de Parejas de Hecho correspondiente. ${ }^{25}$

Ahora bien, en mi opinión, creo que pueden existir argumentos jurídicos bastantes para cuestionar, desde el plano constitucional, el mantenimiento de la existencia de una unión matrimonial como elemento que condiciona, al menos en el terreno estatutario, el ejercicio de este permiso... y ello a pesar de que el Tribunal Constitucional no ha tachado de inconstitucionalidad el precepto. De hecho, en reiteradísimas ocasiones ${ }^{26}$ ha señalado que ambos tipos de convivencia, la marital y la extramarital, son realidades diferentes y no equiparables, protegida la primera por normas de alto nivel (art. $32 \mathrm{CE}$ ), mientras que no así la segunda. Y siendo el derecho a contraer matrimonio un derecho constitucional que los poderes públicos pueden promover y favorecer, se señala como perfectamente legítimo que el legislador establezca diferencias de trato y consecuencias jurídicas más favorables a las uniones matrimoniales que a las puramente fácticas, siempre, claro está, que con ello no se impida a la pareja unirse a través de otras fórmulas de convivencia. Por lo tanto, y en base a este argumento, la expulsión de las parejas de hecho del ámbito de aplicación personal del permiso por matrimonio resulta ser una decisión legislativa perfectamente compatible con las exigencias propias del principio de igualdad; principio que en absoluto impone otorgar un trato unitario a todas las realidades jurídicas que pudieran plantearse. Antes al contrario, porque el tratamiento diferenciador resulta posible, pero siempre y cuando encuentre una justificación objetiva y razonable. Y aquí, en el concreto ámbito de este permiso, siempre parece haber existido tal justificación.

Este tradicional argumento, la no equiparación legislativa entre las parejas unidas en matrimonio y las unidas por otra fórmula de convivencia por tratarse de supuestos distintos, ha llevado, como se sabe, a que se articularan derechos para unas y otras cuyo ejercicio es o bien diferente (piénsese en los requisitos exigidos para que un miembro de

\footnotetext{
${ }^{25}$ Entre otros, pueden citarse el convenio colectivo de Michelín España Portugal, SA, para los centros de trabajo de Tres Cantos (Madrid) y de Illescas (Toledo) (resolución de 19 de junio de 2020) y el convenio colectivo estatal del corcho (resolución de 6 de marzo de 2020), entre muchos otros. También se dan casos en los que el convenio es fiel a la letra del precepto estatutario y extiende todos los permisos que reconoce, menos el de matrimonio, a las parejas de hecho. Claros ejemplos son el convenio colectivo estatal de empresas de seguridad (resolución de 19 de enero de 2018) y el convenio colectivo de Decathlon España, SA. (resolución de 13 de marzo de 2017).

${ }^{26}$ En este sentido, vid. SSTC 184/1990, de 15 de noviembre y 39/1998, de 17 de febrero, entre otras. Siguiendo esta línea, vid. la STS de 22 de octubre de 2019 (Rec. n. ${ }^{\circ}$ 78/2018).
} 
una pareja de hecho pueda lucrar la pensión de viudedad) o bien excluyente, como es el caso del permiso que aquí se trata (y de otros), y ello sin que desde las más altas instancias judiciales se haya planteado la inconstitucionalidad de tales medidas. Ahora bien, en mi opinión, como se dijo, creo que debe ser tiempo ya de avanzar y superar ciertos anacronismos propios de una legislación estatutaria y de una visión de otra época, ajena a las nuevas realidades y cambios sociales.

En efecto, la solución podría ser bien distinta si se optase por un criterio interpretativo o, incluso, reformista de las normas basado en la realidad social del tiempo en que han de ser aplicadas. Y, desde esta perspectiva, el hecho de que el precepto estatutario sólo otorgue el permiso por matrimonio a los supuestos derivados de uniones matrimoniales implica, a mi juicio, un trato desigual prohibido que debería, en una futura reforma, ser atajado. La piedra angular de este planteamiento creo que puede encontrarse en el art. 39 CE. Este es un precepto que, como se sabe, protege a la familia... pero sin que se exprese claramente que la familia a la que hay que tutelar es a la tradicional, a la nacida del vínculo matrimonial. Antes al contrario, pues, de un lado, en el precepto no se contempla una definición del término "familia", por lo que éste puede abarcar muy diversas realidades y, de otro, se señala que "los poderes públicos deberán velar por la protección integral de los hijos, iguales éstos ante la ley -y aquí está el quid de la cuestión-con independencia de su filiación, y de las madres, cualquiera que sea su estado civil" y que los progenitores "deben prestar asistencia de todo orden a los hijos habidos dentro o fuera del matrimonio, durante su minoría de edad y en los demás casos en que legalmente proceda". Si en estos términos se expresa el art. $39 \mathrm{CE}$, restando importancia a que la familia se haya constituido a través del vínculo conyugal ${ }^{27}$ para que deba protegerse y tutelarse a los hijos y a las madres y para que se desplieguen los deberes paternofiliales, quizá pueda plantearse una relectura del precepto en clave actual y en el sentido de convertirlo en el eje a partir del cual pueda sostenerse que la Constitución no establece diferencias entre el matrimonio y otras uniones estables para entender conformada la familia. Argumentación ésta que no entraría en contradicción con lo dispuesto en el art. $32 \mathrm{CE}$, precepto que, aunque coloque a la institución del matrimonio al más alto nivel, lo cierto es que tan sólo contempla el derecho de la pareja a contraerlo, no excluyendo, por tanto, otras opciones igualmente legítimas derivadas del libre desarrollo de la personalidad (art. 10.1 CE).

Lógica consecuencia de este planteamiento es que pueda defenderse la equiparación entre matrimonio y unión estable de convivencia por lo que al permiso del art. 37.3.a) ET se refiere. ¿O acaso concurre en las parejas de hecho alguna necesidad, de la índole que fuera, que justificara otorgarles un tratamiento distinto y específico? La respuesta se muestra, a mi juicio, clara y contundente: ninguna particularidad existe en ellas por la que

\footnotetext{
${ }^{27}$ En este sentido, vid. STC 222/1992, de 11 de diciembre.
} 
quepa defender un tratamiento diferenciador y más gravoso por excluyente. De hecho, si atendemos a la finalidad para la que fue concebido este permiso (conceder ese lapso de tiempo para formalizar la unión y celebrarla), ni sociológica ni jurídicamente puede llegar a pensarse que las parejas de hecho no se encuentren en la misma situación que las unidas por vínculo conyugal. Antes al contrario, porque tanto unas como otras se encuentran, ante el acaecimiento de un mismo suceso (la unión estable), en igual situación jurídica merecedora de idéntica tutela. Por lo tanto, dado que la base de unos supuestos y de otros vendría a ser la misma, podría llegar a defenderse, sin mayores ambages, que la protección dispensada para ambos casos debiera ser también la misma. ${ }^{28}$ Ello no obstante, cabe reconocer que no a toda pareja de hecho se le podría conceder este permiso.

En efecto, obvio es que sí cabría tal reconocimiento cuando de una pareja de hecho formalizada se tratara, entendiendo por tal la que cumpliese con todos los requisitos legales que se le impusieran para su reconocimiento oficial, que deberían ser, básicamente, su inscripción o acreditación notarial como pareja y la inexistencia de vínculo matrimonial anterior para evitar con ello supuestos de uniones no monogámicas. En estos casos en los que existe una relación pública y notoria, acreditada en el plano jurídico, de dos personas que, pudiendo contraer matrimonio entre sí, deciden no hacerlo libremente por los motivos que fueren, ha de reconocerse que existiría el presupuesto de base por el que este permiso fue creado, otorgar cierto tiempo libre para formalizar convenientemente la unión y disfrutar de un lapso temporal para la celebración. No se opondría, sin embargo y a mi parecer, al principio de igualdad una reforma del art. 37.3.a) ET que excluyera a otro tipo de parejas de hecho, las "no formales", del ámbito de aplicación del permiso. Podría parecer ésta una limitación un tanto rigorista; pero lo cierto es que, de algún modo y en algún punto, ha de fijarse la frontera de la protección, pues, a fin de cuentas, de lo que se trata es de conceder un permiso que es retribuido a cargo del empresario y cuya solicitud ha de quedar debidamente justificada. Y así la inscripción registral o, en su caso, la constitución en documento público de la pareja serían los acontecimientos que, como análogos a la boda, determinarían el reconocimiento del derecho al permiso para las uniones more uxorio. Tales medios son, a mi modo de ver, adecuados y proporcionados al fin que con ellos se pretende: acreditar que ha existido una acción deliberada y consciente por parte de ambos miembros de la pareja de proporcionar a su convivencia la pertinente cobertura jurídica, para la que se necesita de tiempo libre para llevarla a cabo y que puede quedar debidamente acreditada ante el empresario. La formalización de la pareja actuaría entonces como relevadora, en el plano del Derecho, de un proyecto de vida estable y sólido -no, por tanto, esporádico, incierto

\footnotetext{
${ }^{28}$ Así se defiende también en el voto particular de la STS de 22 de octubre de 2019 (Rec. n. ${ }^{\text {7 78/2018). }}$
} 
$\mathrm{u}$ oculto a terceras personas-, proporcionando seguridad jurídica al empresario y evitando, en consecuencia, el posible fraude en la utilización del permiso. ${ }^{29}$

Ahora bien, no sólo el permiso de la letra a) del art. 37.3 ET habría de ser objeto de reforma para incorporar a su radio de acción a las parejas de hecho. También lo debería ser el permiso para atender infortunios familiares y ello tanto para promover, como se ha dicho, la equiparación entre los diferentes tipos de uniones, como para sopesar la eliminación del condicionante de la afinidad de los parientes que pueden ser sujetos causantes de esta licencia. En efecto, tal y como se conoce, el permiso contemplado en la letra b) del precepto estatutario citado se activa cuando determinados "parientes" sufren o padecen ciertas contingencias que hacen necesaria la presencia del trabajador a su lado. Estos parientes son los más próximos, los que se extienden hasta el segundo grado por consanguinidad o afinidad y ello con independencia de que exista o no convivencia o roce familiar entre ellos, porque nada exige el precepto.

Pues bien, dejando a un lado el olvido del legislador de los hijos adoptados y que convendría que fuera corregido si nos atenemos a lo estipulado en el art. $108 \mathrm{CC}$, ya de entrada llama la atención, por lo que aquí importa, que no se incluya al cónyuge entre los sujetos causantes del permiso. Ciertamente, como el matrimonio no genera parentesco (art. $915 \mathrm{CC}$ ), al cónyuge no se le puede considerar como a un familiar hasta segundo grado, con lo que, en principio, estaría excluido del radio de acción del precepto. Sin embargo, parece ilógico que pueda denegarse este permiso por accidente, enfermedad, hospitalización, intervención quirúrgica o fallecimiento al cónyuge, máxime cuando es éste el que otorga la protección a los familiares por afinidad. Por ello, no estaría de más, a fin de evitar hipotéticas controversias futuras, que se impusiera una reforma legislativa al respecto. ${ }^{30}$

¿Y qué ocurre con las parejas de hecho? Porque la lógica de incluir al cónyuge en el radio de acción de este permiso, podría no encontrarse cuando de un miembro de la pareja de hecho se tratase, toda vez que podría esgrimirse el mismo argumento que en el caso del permiso por matrimonio: la no equiparación entre las uniones matrimoniales y las no matrimoniales. No obstante y habida cuenta que la familia no matrimonial posee los mismos efectos por lo que se refiere al parentesco que la conyugal y que idéntica carga psicológica puede sufrir el trabajador a causa del infortunio padecido por su pareja de hecho (o, incluso, por los familiares de ésta), parece difícil justificar el tratamiento

\footnotetext{
${ }^{29}$ Entendiendo ello de modo distinto, vid. el convenio colectivo de Beer\&Food (resolución de 13 de junio de 2020) que amplía a la pareja de hecho el permiso por matrimonio exigiendo tan sólo el certificado de convivencia expedido por el Ayuntamiento.

${ }^{30}$ Como ya se hace, por otra parte, en algunos convenios colectivos. Por citar sólo uno, vid. convenio colectivo para el sector de harinas panificables y sémolas (resolución de 4 de junio de 2020).
} 
desigual en estos casos. Si bien se mira, el reconocimiento de este permiso a las parejas unidas de forma no matrimonial no puede suponer desviación alguna de su finalidad, pues la preocupación por la otra persona y el anhelo de proveerla de ayuda en difíciles momentos existirán con independencia de que se hayan contraído o no nupcias. Abunda en esta idea el hecho de que ninguna referencia expresa se realiza en este permiso al matrimonio. La no existencia de tal requerimiento en el tenor literal del art. 37.3.b) ET serviría, de este modo, para avalar, junto con lo dicho anteriormente, una interpretación amplia del ámbito subjetivo de la norma. ${ }^{31}$

Con todo, creo que puede defenderse aquí una diferencia con respecto a lo que se dijo más arriba sobre el permiso por matrimonio. Allí, si se recuerda, se expuso como condicionante de la pareja de hecho que estuviera debidamente constituida. Quedaban excluidas, pues, del radio de acción del permiso el resto de uniones, las parejas de hecho "puras", que no se hubiesen constituido como tales en la forma legalmente prevista para quedar sujetas al régimen jurídico propio de éstas. Pues bien, aquí creo que en buena lógica debe mantenerse una postura distinta, más amplia e integradora. Como antes se ha explicado, que se exija en el caso del permiso por matrimonio la inscripción o formalización de la pareja es del todo punto coherente con la estructura del permiso, que necesita de un acontecimiento a partir del cual pueda computarse el plazo de los quince días y que pueda justificarse ante el empresario. No obstante y en el caso de la licencia que en este epígrafe se aborda, no considero que pueda existir inconveniente alguno para incluir a las uniones no formalizadas, pero estables, en el ámbito subjetivo de aplicación del derecho.

En efecto, en mi opinión, este permiso debe hacerse extensible tanto a las parejas de hecho constituidas formalmente como a las que no lo estén. A las primeras, incluso, sin exigírseles que acrediten una convivencia estable, notoria e ininterrumpida antes del hecho causante, porque si nada de ello se requiere para el resto de parientes sería exagerado, a mi modo de ver, requerírselo a las parejas de hecho que ya hubiesen oficializado su unión. Por un motivo similar, no creo que pueda exigirse que tal formalización deba haber sido realizada con una antelación mínima al hecho causante, bastando, pues, como en el caso del matrimonio, con que se constate la correspondiente inscripción o formalización en documento público para que uno u otro elemento puedan erigirse como hecho constitutivo de la realidad y seriedad, en el plano jurídico, de la pareja. Requerir, además de ello, la verificación de que los convivientes hayan

\footnotetext{
${ }^{31}$ De hecho, ya existen convenios que contemplan a la pareja de hecho como sujeto de causante de este permiso. Así, por citar dos, vid. convenio colectivo de Michelín España Portugal, SA, para los centros de trabajo de Tres Cantos (Madrid) y de Illescas (Toledo) (resolución de 19 de junio de 2020) y convenio colectivo del Grupo de empresas Mercadona, SA, y Forns Valencians Forva, SA, Unipersonal (resolución de 4 de febrero de 2019).
} 
formalizado su unión con cierto lapso temporal de antelación al hecho causante no vendría a ser más, en mi opinión, que una exigencia probatoria duplicada sobre un mismo extremo, la existencia de la pareja de hecho.

Pero, como se ha dicho, no sólo se aboga por extender este derecho a las parejas de hecho formalizadas, sino también a las que no lo estén. A mi modo de ver, el incumplimiento de los requisitos formales constitutivos de la realidad de la pareja no puede ser tomado como causa suficiente para negar a los miembros de otras clases de parejas el disfrute del derecho, porque iguales vínculos afectivos se han podido crear en el seno de una unión formalizada que en el seno de otra no formalizada pero cuyo vínculo es duradero en el tiempo. Cuestión distinta, eso sí, será delimitar qué deba entenderse por tal vínculo duradero. Y aquí, irremediablemente, debe entrar en juego el requisito de la convivencia, pues no de otro modo podría verificarse la existencia de la pareja y su propósito de mantener un proyecto conjunto de vida estable y sólido que, precisamente por su durabilidad, podría haber generado unos vínculos afectivos tales entre sus miembros que sería lo que explicaría, en última instancia, la concesión del permiso.

A estos afectos, podría sostenerse, en este sentido, la aplicación por analogía de los cinco años de convivencia inmediata, notoria e ininterrumpida previstos por el art. 221 LGSS para que el miembro de la pareja de hecho supérstite pueda lucrar la pensión de viudedad. No obstante, exigir tal lapso temporal en este contexto parece excesivo. Cierto es que en la pensión de viudedad tiene su lógica en tanto que entronca directamente con la concesión de una pensión vitalicia a cargo de fondos públicos y las cautelas, a juicio, del legislador deben extremarse. Pero, en el plano que ahora nos ocupa, el disfrute de un permiso de tan corta duración, cinco años se antoja verdaderamente un lapso de tiempo extremadamente dilatado para que a través de él se pueda acreditar la proyección en el tiempo de la pareja y, por ende, su realidad. Por ello, veo más conveniente defender que se entienda la existencia de este vínculo duradero si se acredita un tiempo inferior de convivencia inmediata e ininterrumpida al hecho causante, pero que fuera lo suficientemente extenso (un año tal vez) para que pueda afirmarse que los miembros de la pareja se unen con cierta voluntad de permanencia y con una voluntad conjunta y seria de afecto, socorro y auxilio mutuo. Ello no obstante, tal requisito podría no exigirse si la pareja tuviera descendencia en común, en cuyo caso podría bastar la acreditación de convivencia estable debidamente probada. ${ }^{32}$

Como se ha visto, pues, existen argumentos bastantes para abogar por la reforma del ámbito subjetivo del permiso del art. 37.3.b) ET. No obstante, no son los únicos, pues

\footnotetext{
32 Solución ésta que no es ajena a nuestro ordenamiento jurídico en tanto que ya la incorpora el RD 240/2007, de 16 de febrero, sobre entrada, libre circulación y residencia en España de ciudadanos de los Estados miembros de la Unión Europea y de otros Estados parte en el Acuerdo sobre el Espacio Económico Europeo (art 2.bis).
} 
tales rectificaciones podrían realizarse, igualmente, sobre la base de lo dispuesto en la Directiva (UE) 2019/1158 del Parlamento y del Consejo de 20 de junio de 2019, relativa a la conciliación de la vida familiar y la vida profesional de los progenitores y los cuidadores. Así, el art. 1.e) de tal norma europea dispone que familiares del trabajador son unos muy específicos, a saber: el "hijo, hija, padre, madre o cónyuge del trabajador, o pareja de hecho de éste cuando las uniones de hecho estén reconocidas en el Derecho nacional". Cónyuge y pareja de hecho forman parte, pues, de la familia del trabajador y si esto es así en clave europea, bien podría el legislador nacional tomarlo como referente para acometer una futura reforma del abanico de sujetos causantes que activan el derecho contemplado en el precepto estatutario.

Pero, fíjese, además, en otra particularidad de la norma comunitaria. Ninguna referencia se realiza en ella a los parientes por afinidad, lo que tal vez no sea un desatino. Ciertamente, se podría decir que la Directiva es norma mínima y, en este sentido, la norma estatal la mejora al ampliar el círculo de parientes por los que el trabajador podría ausentarse. Ahora bien, que ello sea así no puede hacer obviar el impacto de género que, como se dijo anteriormente, tiene en concreto esta licencia. No hace falta agotar argumentos ni aportar datos estadísticos para constatar que el cuidado informal recae fundamentalmente sobre la mujer, lo que repercute negativamente en su trabajo y en su tiempo. Su posición familiar también influye, de tal modo que no es infrecuente que deba ocuparse del cuidado, cuando sea necesario, de su familia política, significativamente de sus suegros. Siendo ello así, la Directiva, aquí también, debiera marcar al legislador estatutario la línea a seguir pues los lazos de afinidad pueden convertirse igualmente para la mujer en un "lastre" para su carrera y/o tiempo profesional. En mi opinión, pues, la eliminación del parentesco por afinidad como método desde el cual construir también el espectro de sujetos causantes de la licencia por infortunios familiares podría contribuir a lograr una mayor corresponsabilidad entre hombres y mujeres en este contexto. La idea, además, bien podría extrapolarse y por los mismos motivos a la reducción de jornada por cuidado directo de familiar puesto que aquí el impacto de género es también de indudable calado. De hecho, sobre esta institución ya se ha tenido ocasión de practicar la desaparición de este condicionante, si bien en el marco de una legislación de emergencia como requiere la situación provocada por la COVID-19. ${ }^{33}$ Por lo tanto, claro es que otra forma de legislar es posible, una en la que se tengan más en cuenta las necesidades que conlleva la corresponsabilidad y por la que pueda aumentarse la frecuencia con la que los hombres se acogen a permisos relacionados con la familia.

\footnotetext{
${ }^{33}$ Véase, al respecto, el artículo 6.1 RDLey 8/2020, de 17 de marzo, de medidas urgentes extraordinarias para hacer frente al impacto económico y social del COVID-19.
} 


\section{Referencias bibliográficas}

GONZÁLEZ GONZÁLEZ, Carlos, "La fecha inicial del disfrute de los permisos retribuidos. A propósito de la sentencia del Tribunal Supremo no 145/2018, de 13 de Febrero", Aranzadi Doctrinal, n. ${ }^{\circ}$ 7, 2018, pp. 129-141.

LAHERA FORTEZA, Jesús, "Ejercicio y cómputo de los permisos retribuidos. Comentario a las sentencias del Tribunal Supremo 229/2020 y 257/2020, de 11 y 17 de marzo", Revista de Trabajo y Seguridad Social CEF, n. ${ }^{\circ} 448,2020$, pp. 169-174.

MuÑOZ RuIZ, Ana Belén, "El cómputo de los permisos retribuidos: una revisión de la doctrina judicial y de la reciente cuestión prejudicial", Trabajo y Derecho, n. ${ }^{\circ}$ 53, 2019, pp. 45-56.

Rojo Torrecilla, Eduardo, "Previsible final de la saga “ ¿disfrute de permisos en días laborables o naturales?". Notas a la sentencia de la AN de 6 de julio de 2020, tras la sentencia del TJUE de 4 de junio (asunto C-588/18), y recordatorio de la conflictividad jurídica anterior", El blog de Eduardo Rojo (en línea), 30 de julio de 2020 (http://www.eduardorojotorrecilla.es/2020/07/previsible-final-de-la-saga-disfrutede.html; 3 de agosto de 2020).

SÁncheZ TRIgueros, Carmen, “¿Puede posponerse el disfrute de los permisos por razones familiares al momento en que se debería trabajar?", Revista de Trabajo y Seguridad Social CEF , n. ${ }^{\circ}$ 424, 2018, pp. 135-141.

SÁncheZ Trigueros, Carmen, "Sobre la superposición de permisos a descansos o vacaciones. Comentario a la Sentencia del Tribunal de Justicia de la Unión Europea de 4 de junio de 2020, asunto C-588/18", Revista de Trabajo y Seguridad Social CEF, n. ${ }^{\circ} 451$, 2020, pp. 209-215. 